\title{
Inguinal hernia repair in Switzerland
}

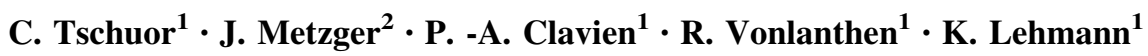

Received: 30 July 2014/Accepted: 19 April 2015/Published online: 7 May 2015

(C) Springer-Verlag France 2015

\begin{abstract}
Purpose Inguinal hernia repair is one of the most common procedures in visceral surgery, and an important teaching operation for residents during their first years. A variety of surgical approaches is currently available, including open surgery with or without mesh and laparoscopic surgery. Here we assessed the current clinical practice for inguinal hernia surgery in Switzerland and the impact on training of surgical residents.

Methods An anonymous online survey was performed among surgical clinics of the Swiss Society of Visceral Surgery (SSVS).

Results The overall response rate was $51 \%$. Nearly all hernia repairs are performed with prosthetic material, and only $3.2 \%$ of the procedures use no mesh. Overall, open surgery is used for $58.5 \%$ of hernias and $41.5 \%$ are operated laparoscopically. In laparoscopic surgery, TEP is the first choice. Overall, the Lichtenstein repair is the classical teaching operation performed by residents in $77.3 \%$ of cases. In contrast to open surgery, laparoscopic hernia repair is not a training operation and residents perform only $9.7 \%$ of laparoscopic hernia repairs.

Conclusion The survey confirms the use of prosthetic material as the standard, and the Lichtenstein repair as the first choice for primary inguinal hernia repair. The
\end{abstract}

K. Lehmann

kuno.lehmann@usz.ch

C. Tschuor

christoph.tschuor@usz.ch

1 Department of Surgery, University Hospital Zurich, Ramistrasse 100, 8091 Zurich, Switzerland

2 Department of Surgery, Cantonal Hospital Lucerne, Spitalstrasse, 6000 Lucerne, Switzerland popularity of laparoscopic hernia surgery is increasing at the price of less teaching operations available for young residents.

Keywords Inguinal hernia repair - Survey $\cdot$ Switzerland

\section{Introduction}

Inguinal hernia is a frequent disease with a peak incidence in male patients in their sixties. In 2011, 16,436 hernia repairs were performed in Switzerland, making it one of the most common surgical procedures according to the federal department of statistics [1]. For many years, the traditional or modified Shouldice technique was considered as the gold standard [2,3]. In Switzerland, many surgeons favored the Barwell repair, using a non-resorbable loop suture for duplication of the transversalis fascia [4]. This changed after the introduction of Lichtenstein's operation using prosthetic material to reinforce the abdominal wall in 1989 , and consequently lowered recurrence rates compared to conventional approaches [5-8]. Meanwhile, a variety of surgical approaches is available, including open approaches with or without mesh placement, and laparoscopic repairs. Laparoscopic repairs showed similar longterm results compared to the Lichtenstein operation but are associated with a more flat learning curve $[9,10]$.

Open inguinal hernia surgery is a classical training operation for young surgical residents in their early residency. The high incidence of the disease, a distinct level of standardization of the procedure and postoperative management, and the clear visualization of anatomical structures make it an ideal teaching operation. Laparoscopic inguinal hernia repair is technically more demanding and associated with more perioperative complications 
according to some studies [11, 12]. The increasing use of laparoscopic hernia surgery may therefore reduce the number of procedures available for basic surgical teaching operations. The aim of the present survey was to assess the current clinical practice and teaching habits of inguinal hernia surgery in Swiss surgical departments.

\section{Materials and methods}

The survey was randomly sent to 25 of 35 clinics of the Swiss Society of Visceral Surgery (SSVS) by email. The SSVS defines training programs and is responsible for the accreditation of visceral surgeons in Switzerland. The clinics were grouped according their SSVS status, into V1 (university hospitals, large regional centers) and V2 (regional centers). With the use of the online tool available on http:// www.surveymonkey.com, all clinics were contacted asking them to participate in the survey. Each participant received a reminder within 1 week after the first email. The survey consisted of 32 questions. Questions consisted of single-item questions, questions asking absolute numbers as well as questions adding up to a $100 \%$ percent. Anonymous data were imported to Excel and analyzed by Graph Pad Prism (Graph Pad Software, La Jolla, CA, USA). Continuous variables were compared with Mann-Whitney $U$ test where appropriate. All items were analyzed statistically. Only relevant and significant results were reported in the manuscript. The Ethics Committee of the Canton of Zurich, Switzerland, approved the protocol of this study.

\section{Results}

\section{Center participation, reply rates and demographics}

Overall, 18 of 25 clinics ( $72 \%$ ) responded to the online questionnaire, eight V1 and ten V2 clinics. The survey therefore represents $51 \%$ of the SSVS clinics. V1 and V2 clinics performed the same number of inguinal hernia repairs with an average of 241.5 per year (range: 100-585).

\section{Watchful waiting}

Generally, the patient's request $(93.30 \%)$, the degree of discomfort and comorbidities (each $53.30 \%$ ) and age $(46.70 \%)$ were most named reasons to choose a "watchful waiting" strategy (Table 1).

\section{The use of a mesh is standard}

Nearly all hernia repairs were performed with prosthetic material. In only $3.22 \%$ of the procedures, no mesh was used, without difference between V1 and V2 clinics. First choice techniques for conventional hernia repair are the Barwell $(55.35 \%)$ and Shouldice $(43.05 \%)$ techniques, while the Bassini repair is only rarely used $(1.60 \%)$. A lightweight mesh is the first choice in the majority $(88.16 \%)$ of V1 and V2 clinics. Alternative methods were only occasionally used, e.g. the Stoppa repair $(9.73 \%)$, mesh and plug $(0 \%)$, or the Prolene hernia system $(0 \%)$ (Table 1$)$.

\section{Open versus laparoscopic approach}

Overall, $58.49 \%$ of the primary and recurrent inguinal hernias are repaired by an open approach, while $41.51 \%$ are operated laparoscopically. The open approach is favored in $63.25 \%$ of the V1 clinics (V1 vs. V2; $p=0.0401$ ), while the open and the laparoscopic approach are chosen with the same frequency (48\%) in V2 clinics. In laparoscopic surgery, TEP is the first choice in V1 $(88.0 \%)$, and in V2 $(58.40 \%)$ clinics. TAPP is performed significantly more often in V2 than in V1 clinics (41.6 vs. $12 \% ; p=0.036$ ). For recurrent hernias, laparoscopic hernia repair is the favored technique in both V1 $(67.5 \%)$ and V2 $(72.0 \%)$ clinics. Similar, a majority (V1 $58.66 \%$ vs. V2 $67.33 \% ; p=0.0125$ ) of inguinal hernias in women are repaired preferentially by laparoscopy (Table 1 ).

\section{Only open hernia repair remains a teaching operation}

Overall, the Lichtenstein repair is the classical teaching operation performed by residents in $77.33 \%$ of cases. In V1 clinics this rate is significantly higher than in V2 clinics (88.8 vs. $69.66 \% ; p=0.0264$ ). Open hernia repair without mesh placement is performed by residents in $60.60 \%$ of cases. The number of procedures needed to perform open hernia repair without supervision was considered $n=22.81$ (V1 vs. V2; $p=0.5598$ ) (Table 1).

In contrast to open surgery, laparoscopic hernia repair is not a training operation, and only $9.66 \%$ of laparoscopic hernia repairs are performed by residents in V1 and V2 clinics. The number of procedures for autonomous surgery for laparoscopic hernia repair was considered $n=35.31$ (Table 1).

\section{Discussion}

The present survey among visceral surgery clinics in Switzerland shows the nearly uniform acceptance of prosthetic material in inguinal hernia surgery, and confirms the Lichtenstein operation as the gold standard in open hernia surgery. In Switzerland, open repair without mesh placement is only used for a minority of patients, traditionally the techniques according Barwell and 
Table 1 Overall reply rates as well as differences between V1 (university hospitals, large regional centers) and V2 (regional centers) clinics

\begin{tabular}{|c|c|c|c|}
\hline & $\mathrm{V} 1$ & $\mathrm{~V} 2$ & Overall $(\mathrm{V} 1+\mathrm{V} 2)$ \\
\hline Number of surgical departments survey was sent to: & 11 & 14 & 25 \\
\hline \multirow[t]{2}{*}{ Number of surgical departments which responded: } & 8 & 10 & 18 \\
\hline & Mean (range) & Mean (range) & Mean (range) \\
\hline Number of inguinal hernias repaired per year (absolute number) & $241.3(100-585)$ & $241.8(141-400)$ & $241.55(100-585)$ \\
\hline Thereof CONVENTIONALLY repaired (\%) & $3.38(0-16)$ & $3.10(0-6)$ & $3.22(0-16)$ \\
\hline Thereof OPEN with MESH repaired (\%) & $63.25(18-100)$ & $48.10(5-90)$ & $55.27(5-100)$ \\
\hline Thereof LAPAROSCOPICALLY repaired (\%) & $33.37(0-80)$ & $48.80(9-95)$ & $41.51(0-95)$ \\
\hline CONVENTIONALLY repaired (\%) & $3.38(0-16)$ & $3.10(0-6)$ & $3.22(0-16)$ \\
\hline According to Shouldice (\%) & $38.12(0-100)$ & $47.00(0-100)$ & $43.05(0-100)$ \\
\hline According to Barwell (\%) & $61.87(0-100)$ & $50.00(0-100)$ & $55.35(0-100)$ \\
\hline Accordig to Bassini (\%) & 0 & $3.00(0-30)$ & $1.6(0-30)$ \\
\hline OPEN with MESH repaired (\%) & $63.25(18-100)$ & $48.10(5-90)$ & $55.27(5-100)$ \\
\hline According to Lichtenstein (\%) & $86.75(18-100)$ & $92.90(36-100)$ & $90.16(18-100)$ \\
\hline With Mesh and Plug (\%) & 0 & 0 & 0 \\
\hline With Prolene Hernia System (\%) & 0 & 0 & 0 \\
\hline According to Stoppa (\%) & $13.25(0-72)$ & $6.90(0-64)$ & $9.73(0-72)$ \\
\hline Others $(\%)$ & 0 & $0.2(0-2)$ & $0.11(0-2)$ \\
\hline LAPAROSCOPICALLY repaired (\%) & $33.37(0-80)$ & $48.80(9-95)$ & $41.51(0-95)$ \\
\hline TEP (\%) & $88.00(20-100)$ & $58.40(0-99)$ & $71.56(0-100)$ \\
\hline TAPP (\%) & $12.00(0-80)$ & $41.6(1-100)$ & $28.44(0-100)$ \\
\hline \multicolumn{4}{|l|}{ Mesh of choice } \\
\hline Heavy-weight Netz (\%) & $6.25(0-50)$ & $16.3(0-100)$ & $11.83(0-100)$ \\
\hline Light-weight Netz (\%) & $93.75(0-100)$ & $83.7(0-100)$ & $88.16(0-100)$ \\
\hline \multicolumn{4}{|l|}{ Technique for recurrent hernia } \\
\hline CONVENTIONAL (\%) & 0 & 0 & 0 \\
\hline OPEN with MESH (\%) & $32.50(10-62)$ & $28.00(0-75)$ & $29.80(0-75)$ \\
\hline LAPAROSCOPICALLY (\%) & $67.50(39-90)$ & $72.00(25-100)$ & $70.20(25-100)$ \\
\hline \multicolumn{4}{|l|}{ Hernia repair in women } \\
\hline CONVENTIONAL (\%) & $1.00(0-5)$ & $6.66(0-50)$ & $4.40(0-50)$ \\
\hline OPEN with MESH (\%) & $40.33(5-100)$ & $26.00(0-100)$ & $31.73(0-100)$ \\
\hline LAPAROSCOPICALLY (\%) & $58.66(0-95)$ & $67.33(0-100)$ & $63.86(0-100)$ \\
\hline \multicolumn{4}{|l|}{ How frequently are hernia repairs performed by the residents? } \\
\hline CONVENTIONAL (\%) & $85.16(60-100)$ & $44.22(0-100)$ & $60.60(0-100)$ \\
\hline OPEN with MESH (\%) & $88.8(70-100)$ & $69.66(20-100)$ & $77.33(20-100)$ \\
\hline LAPAROSCOPICALLY (\%) & $8.30(0-15)$ & $10.5(0-50)$ & $9.66(0-50)$ \\
\hline \multicolumn{4}{|c|}{ Number of procedures needed to performing hernia repair by resident without supervision } \\
\hline CONVENTIONAL $(n)$ & $18.57(0-50)$ & $26.11(0-100)$ & $22.81(0-100)$ \\
\hline OPEN with MESH $(n)$ & $17.14(0-50)$ & $27.22(0-100)$ & $22.81(0-100)$ \\
\hline LAPAROSCOPICALLY $(n)$ & $30.00(0-50)$ & $39.44(0-100)$ & $35.31(0-100)$ \\
\hline \multicolumn{4}{|l|}{ Indications for "watchful waiting" } \\
\hline Age $(\%)$ & & & 46.7 \\
\hline Degree of discomfort (\%) & & & 53.3 \\
\hline Comorbidities (\%) & & & 53.3 \\
\hline Patient's request $(\%)$ & & & 93.3 \\
\hline
\end{tabular}

Shouldice are most favored [4]. The popular use of a mesh is consistent with the recommendation of a recent meta-analysis of sixteen RCT's, favoring the use of a mesh due to lower recurrence rates compared to non-mesh repairs [13]. The nearly uniform use of light-weight mesh types for inguinal hernia surgery is supported by a recent 
meta-analysis, suggesting lower rates of chronic groin pain compared to heavy-weight mesh [14]. In contrast, although the mesh and plug showed similar outcomes after 1 year compared to the Lichtenstein technique in a recent randomized trial [15], this alternative technique did not find the way into clinical routine. The open preperitoneal technique according to Stoppa has met particular success in the repair of bilateral hernias, recurrent or rerecurrent hernias and female inguinal hernias [16, 17]. Overall, the survey corroborates established standards in open hernia surgery. The role of laparoscopic hernia surgery is more ambiguous. Our data show an increasing popularity of TEP and TAPP for primary hernia surgery, particularly in V2 clinics. Potential medical reasons are some short-term benefits of laparoscopic hernia surgery with quicker return to normal activity, and fewer wound problems shown in some trials [18, 19]. One Cochrane review concerned the higher serious complication rate of laparoscopic hernia repair regarding injury to visceral organs (bladder) and vascular injuries [20]. In addition, the benefits of laparoscopy are less obvious on the long term, one meta-analysis even suggests higher recurrence rates for TEP compared to Lichtenstein repair [21]. Despite no clear benefit regarding long-term outcome in several RCTs, laparoscopy may have technical advantages in particular situations [22]. For example, in patients with recurrent inguinal hernia, laparoscopy showed less acute and chronic pain, and patients returned earlier to work compared to Lichtenstein repair [23]. This situation is similar for hernia in woman, where laparoscopy is often favored, also stated by the majority of Swiss centers. However, given the current evidence from several trials regarding long-term results for chronic pain and recurrence rates, the popularity of laparoscopic inguinal hernia surgery is not solely based on medical reasons. Indeed, it is not clear why there is more laparoscopic repair in V2 than in V1 clinics. Rather, personal preference or patient marketing may influence the decision to advocate either the Lichtenstein repair or laparoscopic TEP or TAPP.

A major concern is the dramatic loss of available teaching operations in this essential field of basic surgical training. The increasing use of laparoscopy for primary inguinal hernia repair shifts a classic teaching operation for young residents to a technically challenging operation for more experienced surgeons. Visualization of anatomical structures is far more ambitious in laparoscopic repairs, and the risk of major intraoperative complications is higher [21]. The learning curve for endoscopic approaches could possibly be steepened by simulation-based training [24] or surgical training courses.

With a response rate of $72 \%$, the present survey provides a representative overview on the current clinical practice for inguinal hernia surgery. However, we would like to account some limitations. Inguinal hernia surgery is a core competence and important teaching operation of the selected SSVS clinics (V1, V2). However, an important number of procedures are performed outside the SSVS, and these data are not represented. Data were collected anonymously and a reporting bias cannot be excluded.

In conclusion, the Lichtenstein operation is currently the preferred technique for inguinal hernia repair in Switzerland, generally in the setting of a teaching operation. An increasing number of procedures are performed by laparoscopy, requiring more advanced surgical skills and experience. For teaching reasons, this should be addressed in the current training programs.

Conflict of interest The authors declare that they have no competing interests. CT declares no conflict of interest. JM declares no conflict of interest. PAC declares no conflict of interest. RV declares no conflict of interest. KL declares no conflict of interest.

\section{References}

1. http://www.bfs.admin.ch/bfs/portal/de/index/themen/14/04/01/ data/01/05.html

2. Lichtenstein IL, Shulman AG, Amid PK, Montllor MM (1989) The tension-free hernioplasty. Am J Surg 157(2):188-193

3. Schumpelick V, Treutner KH, Arlt G (1994) Inguinal hernia repair in adults. Lancet 344(8919):375-379 S0140-6736(94)914044 [pii]

4. Striffeler H, Zufferey S, Schweizer W (1993) Quality control after introduction of a new hernia technique. Barwell transversal fascia-plasty. Helvetica chirurgica acta 59(5-6):771-774

5. Beets GL, Oosterhuis KJ, Go PM, Baeten CG, Kootstra G (1997) Longterm followup (12-15 years) of a randomized controlled trial comparing Bassini-Stetten, Shouldice, and high ligation with narrowing of the internal ring for primary inguinal hernia repair. J Am Coll Surg 185(4):352-357

6. Bendavid R (1989) New techniques in hernia repair. World J Surg 13(5):522-531

7. Shulman AG, Amid PK, Lichtenstein IL (1995) A survey of nonexpert surgeons using the open tension-free mesh patch repair for primary inguinal hernias. Int Surg 80(1):35-36

8. Vrijland WW, van den Tol MP, Luijendijk RW, Hop WC, Busschbach JJ, de Lange DC, van Geldere D, Rottier AB, Vegt PA, IJ JN, Jeekel J (2002) Randomized clinical trial of non-mesh versus mesh repair of primary inguinal hernia. Br J Surg 89(3):293-297. doi:10.1046/j.0007-1323.2001.02030.x

9. Neumayer L, Giobbie-Hurder A, Jonasson O, Fitzgibbons R, Dunlop D, Gibbs J, Reda D, Henderson W (2004) Open mesh versus laparoscopic mesh repair of Inguinal Hernia. N Engl J Med 350(18):1819-1827. doi:10.1056/NEJMoa040093

10. Zendejas B, Onkendi EO, Brahmbhatt RD, Lohse CM, Greenlee SM, Farley DR (2011) Long-term outcomes of laparoscopic totally extraperitoneal inguinal hernia repairs performed by supervised surgical trainees. Am J Surg 201(3):379-383. doi:10.1016/ j.amjsurg.2010.08.019 discussion 383-374

11. Neumayer L, Giobbie-Hurder A, Jonasson O, Fitzgibbons R Jr, Dunlop D, Gibbs J, Reda D, Henderson W (2004) Open mesh 
versus laparoscopic mesh repair of inguinal hernia. N Engl J Med 350(18):1819-1827. doi:10.1056/NEJMoa040093

12. The MRC Laparoscopic Groin Hernia Trial Group (1999) Laparoscopic versus open repair of groin hernia: a randomised comparison. Lancet 354(9174):185-190

13. Amato B, Moja L, Panico S, Persico G, Rispoli C, Rocco N, Moschetti I (2012) Shouldice technique versus other open techniques for inguinal hernia repair. Cochrane Database Syst Rev 4:CD001543. doi:10.1002/14651858.CD001543.pub4

14. Sajid MS, Leaver C, Baig MK, Sains P (2012) Systematic review and meta-analysis of the use of lightweight versus heavyweight mesh in open inguinal hernia repair. Br J Surg 99(1):29-37. doi:10.1002/bjs. 7718

15. Frey DM, Wildisen A, Hamel CT, Zuber M, Oertli D, Metzger J (2007) Randomized clinical trial of Lichtenstein's operation versus mesh plug for inguinal hernia repair. $\mathrm{Br} \mathrm{J}$ Surg 94(1):36-41. doi:10.1002/bjs.5580

16. Fernandez-Lobato R, Tartas-Ruiz A, Jimenez-Miramon FJ, Marin-Lucas FJ, de Adana-Belbel JC, Esteban ML (2006) Stoppa procedure in bilateral inguinal hernia. Hernia J Hernias Abdom Wall Surg 10(2):179-183. doi:10.1007/s10029-005-0061-3

17. Kurzer M, Belsham PA, Kark AE (2002) Prospective study of open preperitoneal mesh repair for recurrent inguinal hernia. Br J Surg 89(1):90-93. doi:10.1046/j.0007-1323.2001.01956.x

18. Memon MA, Cooper NJ, Memon B, Memon MI, Abrams KR (2003) Meta-analysis of randomized clinical trials comparing open and laparoscopic inguinal hernia repair. $\mathrm{Br} \mathrm{J}$ Surg 90(12):1479-1492. doi:10.1002/bjs.4301

19. Langeveld HR, van't Riet M, Weidema WF, Stassen LP, Steyerberg EW, Lange J, Bonjer HJ, Jeekel J (2010) Total extraperitoneal inguinal hernia repair compared with Lichtenstein (the LEVEL-Trial): a randomized controlled trial. Ann Surg 251(5):819-824. doi:10.1097/SLA.0b013e3181d96c32

20. McCormack K, Scott NW, Go PM, Ross S, Grant AM, Collaboration EUHT (2003) Laparoscopic techniques versus open techniques for inguinal hernia repair. Cochrane Database Syst Rev 1:CD001785. doi:10.1002/14651858.CD001785

21. O'Reilly EA, Burke JP, O'Connell PR (2012) A meta-analysis of surgical morbidity and recurrence after laparoscopic and open repair of primary unilateral inguinal hernia. Ann Surg 255(5):846-853. doi:10.1097/SLA.0b013e31824e96cf

22. Karthikesalingam A, Markar SR, Holt PJ, Praseedom RK (2010) Meta-analysis of randomized controlled trials comparing laparoscopic with open mesh repair of recurrent inguinal hernia. $\mathrm{Br}$ J Surg 97(1):4-11. doi:10.1002/bjs.6902

23. Kouhia ST, Huttunen R, Silvasti SO, Heiskanen JT, Ahtola H, Uotila-Nieminen M, Kiviniemi VV, Hakala T (2009) Lichtenstein hernioplasty versus totally extraperitoneal laparoscopic hernioplasty in treatment of recurrent inguinal hernia-a prospective randomized trial. Ann Surg 249(3):384-387. doi:10. 1097/SLA.0b013e318196d0b0

24. Zendejas B, Cook DA, Bingener J, Huebner M, Dunn WF, Sarr MG, Farley DR (2011) Simulation-based mastery learning improves patient outcomes in laparoscopic inguinal hernia repair: a randomized controlled trial. Ann Surg 254(3):502-509. doi:10. 1097/SLA.0b013e31822c6994 